\title{
Testing the hierarchical SDT model: the case of performance-oriented classrooms
}

\author{
Hanneke J. C. Van Nuland • Toon W. Taris • \\ Monique Boekaerts $\cdot$ Rob L. Martens
}

Received: 3 December 2010 /Revised: 17 August 2011 / Accepted: 15 November 2011 /

Published online: 21 December 2011

(C) The Author(s) 2011. This article is published with open access at Springerlink.com

\begin{abstract}
The self-determination theory (SDT) assumes that healthy motivation needs to be intrinsic in nature and that the basic psychological needs competence, autonomy and relatedness are prerequisites for intrinsically motivated behaviour. Intrinsically motivated students in turn show more persistence and understanding of classroom material. However, in secondary education, students often participate in performance-oriented classrooms with an extrinsic orientation and it cannot be assumed that the principles advocated by the SDT are automatically applicable in this context. We tested a model relating basic psychological needs via intrinsic motivation to persistence and performance at two waves using data from 476 students (aged 11-17 years) attending pre-vocational secondary education. Structural equation analysis showed that a partial mediation model with perceived competence also directly associated with persistence and performance fitted the data best at both waves. Interestingly, the strength of the effects varied across waves, such that relatedness and
\end{abstract}

H. J. C. Van Nuland $(\bowtie) \cdot$ M. Boekaerts $\cdot$ R. L. Martens

Leiden University, Leiden, The Netherlands

e-mail: hanneke.knoop@cito.nl

M. Boekaerts

e-mail: boekaerts@fsw.leidenuniv.nl

R. L. Martens

e-mail: rob.martens@ou.nl

H. J. C. Van Nuland

Cito Arnhem (National Institute for testing and assessment), Arnhem, The Netherlands

T. W. Taris

Utrecht University, Utrecht, The Netherlands

e-mail: t.taris@uu.nl

M. Boekaerts

K.U. Leuven, Leuven, Belgium

R. L. Martens

Ruud de Moor Centre, Open University, Heerlen, The Netherlands 
autonomy became negative predictors of intrinsic motivation for a familiar task. The practical and theoretical implications of these findings are discussed.

Keywords Self-determination theory · Structural equation modelling · Adolescents · Learning

The importance of classroom motivation in secondary education is undisputed. Unfortunately, there are many motivational problems in the classroom. Students in their early adolescence show a decline in motivation and interest in school (e.g. Eccles et al. 1993). Additionally, late adolescent students show a general decline in achievement and mastery goals compared to younger students (Mansfield and Wosnitza 2010).

Furthermore, in class, there is a strong emphasis on performance and extrinsic motivation. Teachers evaluate and monitor learning by grading their students' performance (Ryan and Weinstein 2009). As a consequence, classroom performance is commonly assessed with tests and exams, which may lead students towards extrinsic orientations. According to the self-determination theory (SDT; Deci and Ryan 2000), under such conditions, feelings of enthusiasm and interest are in danger of being replaced by experiences of anxiety, boredom and alienation (Niemiec and Ryan 2009). Imposing external control might even disrupt students' natural tendency to learn. Therefore, the present study was designed to test the predictions generated by SDT in a predominantly extrinsically oriented context.

\section{Self-determination theory: research findings}

SDT is a universal motivation theory that is presumed to apply to individuals of all age groups across all situations (Ryan and Deci 2000b). This implies that SDT can also be applied in the educational context (Reeve 2002). SDT proposes that people have a natural tendency to learn. Within SDT, the concept of motivation can either be intrinsic or extrinsic. Ryan and Deci (2000a) postulate that extrinsic motivation can vary in the degree to which it is autonomous, which results in four different sub-categories of extrinsic motivation depending on the amount of internalisation and regulatory style of adopting a specific goal. The taxonomy of human motivation contains six different motivation styles. At the left is amotivation, which is the lack of any intention to act. In the middle of the taxonomy, the four different sub-categories of extrinsic motivation are represented. And at the right of the taxonomy, intrinsic motivation is to be retrieved. Intrinsic motivation refers to the motive to engage in activities for the joy that pursuing the activity itself gives, as distinguished from extrinsic motivation where behaviour relies on external rewards (Deci and Ryan 1985). Research has emphasised the importance of creating a favourable learning environment in order to elicit intrinsic motivation. Deci and Ryan's SDT states that intrinsic motivation flourishes when three psychological needs are fulfilled in the learning environment. These are the perception of autonomy, a feeling of competence and experiencing social relatedness. Thus, in order to establish or maintain intrinsic motivation, students must experience their behaviour to be self-determined (i.e. the perception of autonomy), experience the feeling of competence or efficacy during action (i.e. the perception of competence) and experience a sense of belongingness and connectedness to classmates and the teacher (i.e. the perception of social relatedness) (Ryan and Deci 2000a). The full model, as described in Deci and Ryan (1985) and Ryan and Deci (2000a) with the 
taxonomy of human motivation, is not the scope of this paper. We will present and investigate the hierarchical model of motivation according to SDT (Vallerand 1997) as depicted in Fig. 1.

Many studies confirmed parts of the model that underlies SDT. For instance, it has been shown that intrinsic motivation elicits positive behaviour including persistence, preference for understanding and curiosity, which in turn results in better performance (Reeve 2002; Ryan and Deci 2000a). Various studies document aspects of the SDT framework in educational contexts (e.g. see Table 1; Benware and Deci 1984; Burton et al. 2006; Grolnick and Ryan 1987; Koestner et al. 1984; Ryan and Grolnick 1986; Standage et al. 2006; Tsai et al. 2008). However, only few studies in this area have captured the hierarchical SDT model as a whole. Therefore, as yet it is largely unclear how the components in the model are exactly related (i.e. full or partial mediation, see below) and what the strength and direction of the paths within the SDT model are. One notable exception is Chen and Jang's (2010) study, which attempted to test the SDT (omitting the need for relatedness) model in an online learning environment, but failed to find support for motivation to predict learning outcomes (for a study among undergraduates that supported the same model, but see Grouzet et al. 2004). The evidence is even scarcer for the age group examined in the present article. Véronneau et al. (2005) claimed to be the first to investigate the applicability of SDT within an adolescent group of students. They reported positive associations between competence, autonomy and relatedness with adolescent well-being. Although their findings are largely in line with the hierarchical model of motivation (Vallerand 1997), it cannot be denied that, to date, the evidence is sparse and that there is a definite need to probe the model's assumptions further than has currently been done.

A particular challenge is that current research in this area does not always take into account the temporal dynamics among the key concepts of SDT when investigating the hierarchical SDT model in the classroom. For example, classroom learning is often characterised by a repetition of the same subject matter in varying contexts and degrees of difficulty. This implies that the subject matter is basically the same, and there is little doubt that this will be evident to students, if only because teachers may refer their students to already-discussed parts of the textbook for further explanation of the tasks to be conducted. It is unclear whether the presumed associations among the concepts of SDT hold when the learning situation is characterised by a high degree of repetitiveness. In the present study, the subject matter is indeed repetitive in the classroom, whereas it concerns the practice of revision skills together with grammar skills.

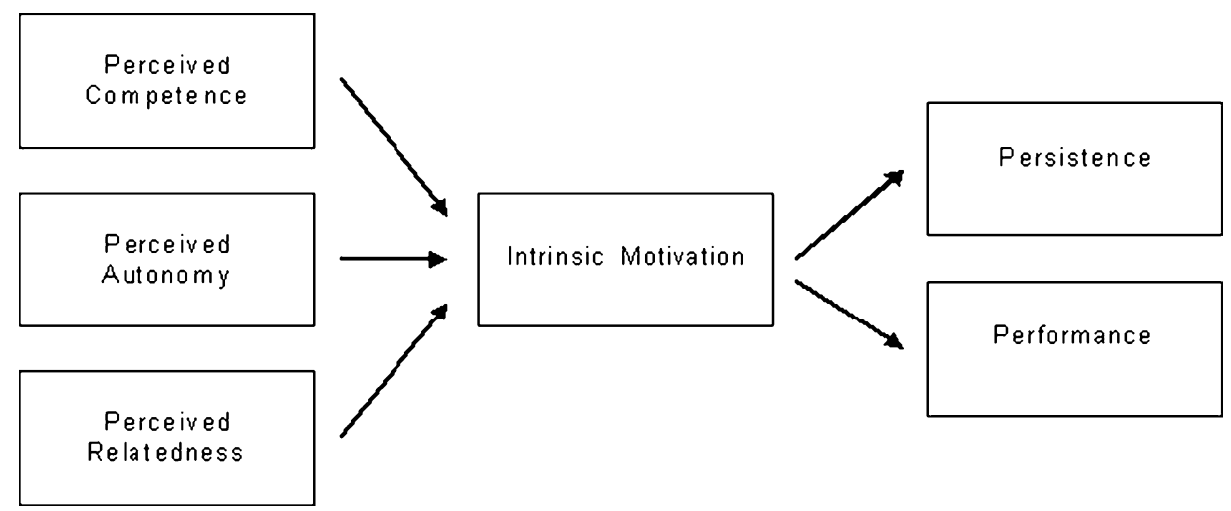

Fig. 1 The theory-based hierarchical SDT model 
Table 1 Examples of prior research

\begin{tabular}{|c|c|c|c|}
\hline Authors & $\begin{array}{l}\text { Aspects of the } \\
\text { hierarchical } \\
\text { SDT model } \\
\text { investigated }\end{array}$ & Outcome of the study & $\begin{array}{l}\text { Aspects of the hierarchical } \\
\text { SDT model not investigated }\end{array}$ \\
\hline $\begin{array}{l}\text { Benware and Deci } \\
\text { (1984) }\end{array}$ & $\begin{array}{l}\text { Extrinsic motivation, } \\
\text { intrinsic motivation, } \\
\text { performance, social } \\
\text { relatedness }\end{array}$ & $\begin{array}{l}\text { Subjects with an intrinsic } \\
\text { orientation are more } \\
\text { intrinsically motivated, } \\
\text { have higher conceptual } \\
\text { learning scores and } \\
\text { perceive themselves to } \\
\text { be more actively engaged } \\
\text { with the environment than } \\
\text { subjects with an extrinsic } \\
\text { orientation }\end{array}$ & $\begin{array}{l}\text { Perceived autonomy, } \\
\text { perceived competence, } \\
\text { persistence }\end{array}$ \\
\hline $\begin{array}{l}\text { Burton et al. } \\
\text { (2006) }\end{array}$ & $\begin{array}{l}\text { Intrinsic motivation, } \\
\text { extrinsic motivation, } \\
\text { psychological } \\
\text { well-being, } \\
\text { performance }\end{array}$ & $\begin{array}{l}\text { Intrinsic orientation predicts } \\
\text { psychological well-being, } \\
\text { independent of academic } \\
\text { performance. Extrinsic } \\
\text { orientation predicts } \\
\text { academic performance }\end{array}$ & $\begin{array}{l}\text { Perceived competence, } \\
\text { perceived autonomy, } \\
\text { social relatedness, } \\
\text { persistence }\end{array}$ \\
\hline $\begin{array}{l}\text { Grolnick and Ryan } \\
\text { (1987) }\end{array}$ & $\begin{array}{l}\text { Perceived autonomy, } \\
\text { interest, conceptual } \\
\text { learning }\end{array}$ & $\begin{array}{l}\text { Higher perceived autonomy } \\
\text { results in higher interest } \\
\text { and conceptual learning }\end{array}$ & $\begin{array}{l}\text { Perceived competence, } \\
\text { social relatedness, } \\
\text { performance, } \\
\text { persistence }\end{array}$ \\
\hline $\begin{array}{l}\text { Koestner et al. } \\
\text { (1984) }\end{array}$ & $\begin{array}{l}\text { Perceived autonomy, } \\
\text { intrinsic motivation, } \\
\text { performance }\end{array}$ & $\begin{array}{l}\text { Intrinsic motivation, enjoyment, } \\
\text { creativity and quality of artistic } \\
\text { production decrease when students } \\
\text { experience low autonomy }\end{array}$ & $\begin{array}{l}\text { Perceived competence, } \\
\text { social relatedness, } \\
\text { persistence }\end{array}$ \\
\hline $\begin{array}{l}\text { Ryan and Grolnick } \\
\text { (1986) }\end{array}$ & $\begin{array}{l}\text { Perceived autonomy, } \\
\text { intrinsic motivation }\end{array}$ & $\begin{array}{l}\text { Higher perceived autonomy } \\
\text { results in higher perceived self } \\
\text { worth, cognitive competence, } \\
\text { internal control and mastery } \\
\text { motivation }\end{array}$ & $\begin{array}{l}\text { Perceived competence, } \\
\text { social relatedness, } \\
\text { performance, } \\
\text { persistence }\end{array}$ \\
\hline $\begin{array}{l}\text { Standage et al. } \\
\text { (2006) }\end{array}$ & $\begin{array}{l}\text { Perceived autonomy, } \\
\text { perceived competence, } \\
\text { social relatedness, } \\
\text { intrinsic motivation, } \\
\text { persistence }\end{array}$ & $\begin{array}{l}\text { Students who perceive an } \\
\text { autonomy-supportive } \\
\text { environment experience } \\
\text { greater levels of } \\
\text { autonomy, competence and } \\
\text { relatedness and have higher } \\
\text { intrinsic motivation }\end{array}$ & Performance \\
\hline $\begin{array}{l}\text { Tsai et al. } \\
\text { (2008) }\end{array}$ & $\begin{array}{l}\text { Perceived autonomy, } \\
\text { intrinsic motivation }\end{array}$ & $\begin{array}{l}\text { Perceived autonomy predicts } \\
\text { intrinsic motivation in the } \\
\text { classroom }\end{array}$ & $\begin{array}{l}\text { Perceived competence, } \\
\text { social relatedness, } \\
\text { performance, } \\
\text { persistence }\end{array}$ \\
\hline
\end{tabular}

\section{Self-determination theory tested in the classroom}

With this study, we tried to find support for the hierarchical SDT model with data collected at two waves within secondary education. SDT assumes that the model is applicable to every situation at all times. Therefore, our first hypothesis is that we will find support for the fully mediated SDT model as presented in Fig. 1 at both points in time. Intrinsic motivation is expected to mediate the association between students' psychological needs and their performance and persistence. Thus, we expect that the perceived opportunity for autonomy, students' perceived competence and experienced relatedness before engaging in 
a task affect intrinsic motivation and that, in turn, higher intrinsic motivation will elicit better performance and higher persistence.

However, the perceived autonomy, competence and relatedness might also directly influence performance and persistence. There is research evidence that the SDT model might be a partially mediated model. For instance, Black and Deci (2000) showed that increased teachers' autonomy support directly increases performance. Our alternative hypothesis is that we will find support for a partially mediated model. This means that the three psychological needs indirectly (through intrinsic motivation) and directly influence the outcome variables performance and persistence at both waves.

Next to the indistinctness about the nature of the relations in the theory-based model of SDT (Fig. 1), the strength and direction of the paths within the SDT model may vary across time. This may especially be the case in classroom settings where tasks often have a strongly repetitive character. For example, in the present study, the characteristics of the task are repeated in order to practice revision and grammar skills. This repetition results in learning, as students familiarise themselves with the application of novel knowledge. However, this approach may run counter to the principles of SDT. Deci and Ryan (2000b) stated that: 'Intrinsic motivation concerns active engagement with tasks that people find interesting and that, in turn, promote growth. Such activities are characterized by novelty' (p. 233). Students' motivation will initially be triggered by learning tasks that give a sense of novelty (Chen and Darst 2001); this may change when the task is no longer perceived as challenging. Elsewhere, Van Nuland et al. (submitted for publication) suggested that students' expectations will be different when they are working on an unfamiliar task or on the same task some time later (familiar task). This implies that students' needs (i.e. perceived autonomy, competence and relatedness) might also differ when working on a familiar task versus an unfamiliar task. Students are unlikely to be motivated if they are in an environment that does not meet their psychological needs (Eccles et al. 1993). Before entering a learning environment, students have expectations about the learning task which influence subsequent perceptions (Könings et al. 2008). It is likely that students will adjust their expectations when they are asked to do the same or a similar task again. In an experimental setting, this would imply that, after students have worked on an unfamiliar task at wave 1, they might adjust their expectations for the same or a similar task at wave 2. For instance, Minnaert et al. (2007) already found that students in vocational secondary education experienced a different level of need fulfilment while working on a group project during separate occasions during the school year. At the beginning of the course, intrinsically motivated students experienced fulfilment of their need for relatedness and need for competence, whereas later on in the course, the need for relatedness combined with the need for autonomy determined intrinsic motivation.

In the classroom, students are often confronted with repetitive tasks. Investigating the applicability of the SDT model in relation to unfamiliar and familiar tasks is, therefore, interesting and crucial. Based on the notions discussed above, our second hypothesis is that the SDT model (either fully or partially mediated) may change depending on the students' perception of the familiarity of the task.

In sum, our hypotheses within and across the two waves are:

1a. (i) The fully mediated model at wave 1 (unfamiliar task) will be supported;

(ii) The fully mediated model at wave 2 (familiar task) will be supported;

1b. Alternative hypothesis:

(i) The partially mediated model at wave 1 (unfamiliar task) will be supported;

(ii) The partially mediated model at wave 2 (familiar task) will be supported;

2. The strength of the effects of the path model will vary across waves. 


\section{Method}

Sample

Five secondary education schools participated on a voluntary basis on two occasions separated by a 6-month interval $\left(N=476,54 \%\right.$ boys, $\left.M_{\text {age }}=14.08, \mathrm{SD}=1.03\right)$. During the study, students worked on a native language task in order to practice their revision and grammar skills. Education in all schools was organised according to comparable, traditional educational principles. The characteristics of these traditional schools were teacher-centred instruction, direct instruction based on textbooks, lectures and individual assignments and a single, unified curriculum for all students, regardless of ability or interest. Students' achievement in these schools is assessed with tests and exams, which result in passing or failing grade. Students in all four grade levels of pre-vocational secondary education participated in the study.

Instruments

\section{Performance}

In cooperation with experienced teachers in the secondary education context, comparable language tasks for each grade were developed. These tasks measured revision skills based on the writing revision problems task developed by Zimmerman and Kitsantas (1999). Students had to revise two or three short sentences into a single inclusive, but nonredundant sentence (for an example of the task in the 11th grade, see Fig. 2). The sentences were scored on technical writing aspects (e.g. spelling, grammar) and content (i.e. primary and secondary main words) according to a correction procedure designed for Dutchspeaking students by Boekaerts et al. (2008). Performance was computed as the sum of the scores on technical and content aspects. Note that performance scores on the different tasks were only comparable within the same grade because each grade had its own tasks. Therefore, performance values were $z$-standardised separately within grade group before analysing the data. Although it was made sure that the assignment was in line with the curriculum and comparable to other tasks used in the participating schools, the task was an unfamiliar task for the students in experiment 1. Students in experiment 2 already participated in experiment 1 and were familiar with the task. Before participating in experiment 2, students were told that their task in this experiment would be similar to what they did during experiment 1 . To measure the reliability of the scoring system, a second coder scored 10 assignments of each task in each different grade. Agreement was assessed by computing coherence $(r)$ between the two coders. The average coherence in the sample was $88 \%$. Disagreements were solved through discussion and this resulted in minor revision of the scoring system. All normality assumptions of the revision tasks were satisfied.

They tried to examine parts of their bodies which they normally cannot see. The elephants moved their trunks to look into their mouths.

Revision:

The elephants used their trunks to look into their mouths.

Fig. 2 Example of the revision task 


\section{Motivation}

Information on intrinsic motivation was collected with four 7-point Likert scale items ('is very unlike me' versus 'is very like me'). This subscale was derived from the interest/ enjoyment subscale of Ryan and Deci's Intrinsic Motivation Inventory (IMI) and the version used was already validated in a similar context (Van Nuland et al. 2010). A sample item is 'This assignment will be fun to do'. Cronbach's $\alpha$ of this subscale was 0.83 in experiment 1 and 0.81 in experiment 2 .

With the same 7-point Likert scale, 13 items assessed persistence after the task (e.g. 'I'm curious to know how I can apply these skills again'). This scale was validated in a similar context (Van Nuland et al., submitted for publication; Van Nuland et al. 2010). Cronbach's $\alpha$ of this subscale was 0.86 in experiment 1 and 0.87 in experiment 2 .

Needs

The needs competence, autonomy and relatedness were assessed with three subscales with the same 7-point Likert scale. The subscales perceived competence and autonomy were derived from Ryan and Deci's IMI (validated by McAuley et al. 1989). Perceived relatedness was assessed with a subscale based on the Questionnaire for Social Support developed by Boekaerts (1987). Table 2 presents sample items and internal consistency for both time points. Note that Cronbach's $\alpha$ of the relatedness subscale was below the Cronbach and Shavelson (2004) standard of acceptable reliability $(\geq 0.70)$. Our conclusions with regard to relatedness will be drawn with caution.

\section{Procedure}

The design and procedure for both experiments was exactly the same. All participants had informed consent of their parents and received two comparable language tasks during two lessons of a native language class. Data collection at both time points took place during one lesson (maximum of $45 \mathrm{~min}$ ) of a native language class in the normal classroom context with both the teacher and researcher present. The task was introduced by the teacher as part of the normal curriculum. Students had to revise two or three short sentences into a single inclusive, but non-redundant sentence. After the teacher read out loud the standardised instruction, participants could autonomously read the instruction for the sentence revision tasks. Questionnaires on motivation variables collected information before (i.e. intrinsic motivation and psychological need satisfaction) and after (i.e. persistence) working on the sentence revision tasks. Experiments 1 and 2 were separated by a 6-month interval.

Table 2 Sample items of SDT variables

\begin{tabular}{llll}
\hline & Sample item & $\alpha_{1}$ & $\alpha_{2}$ \\
\hline Competence & I feel confident that I can do this assignment & 0.76 & 0.79 \\
Autonomy & I can decide for myself how to do this assignment & 0.70 & 0.72 \\
Relatedness & I feel at ease in this class & 0.55 & 0.60 \\
Intrinsic motivation & This assignment will be fun to do & 0.83 & 0.81 \\
Persistence & I'm curious to know how I can apply these skills again & 0.86 & 0.87 \\
\hline
\end{tabular}


Table 3 Means, standard deviations, and correlations among the study variables

\begin{tabular}{|c|c|c|c|c|c|c|c|c|}
\hline & $M$ & SD & 1a & $1 b$ & $1 \mathrm{c}$ & 2 & $3 a$ & $3 b$ \\
\hline \multicolumn{9}{|l|}{ Wave 1} \\
\hline 1a Perceived relatedness & 5.44 & 1.01 & - & & & & & \\
\hline 1b Perceived autonomy & 4.90 & 1.45 & $0.18^{*}$ & - & & & & \\
\hline 1c Perceived competence & 5.16 & 1.14 & $0.38^{*}$ & $0.23 *$ & - & & & \\
\hline 2 Intrinsic motivation & 3.47 & 1.38 & $0.21 *$ & 0.02 & $0.30 *$ & - & & \\
\hline 3a Persistence & 3.51 & 1.01 & $0.21 *$ & $0.10^{* *}$ & $0.28 *$ & $0.56^{*}$ & - & \\
\hline 3b Performance & - & - & 0.04 & -0.01 & 0.02 & 0.06 & 0.07 & - \\
\hline \multicolumn{9}{|l|}{ Wave 2} \\
\hline 1a Perceived relatedness & 5.29 & 1.40 & - & & & & & \\
\hline 1b Perceived autonomy & 4.94 & 1.46 & $0.27 *$ & - & & & & \\
\hline 1c Perceived competence & 4.85 & 1.27 & $0.35^{*}$ & $0.35^{*}$ & - & & & \\
\hline 2 Intrinsic motivation & 2.95 & 1.32 & $-0.09 * *$ & $-0.16^{*}$ & $0.12 *$ & - & & \\
\hline 3a Persistence & 3.33 & 0.98 & 0.05 & 0.02 & $0.25^{*}$ & $0.50 *$ & - & \\
\hline 3b Performance & - & - & 0.09 & 0.05 & $0.13^{*}$ & 0.05 & -0.01 & - \\
\hline
\end{tabular}

Performance scores were standardised, hence $M=0$ and $\mathrm{SD}=1$

${ }^{*} p=0.01, * * p=0.05$; significant correlation (two-tailed)

\section{Statistical analyses}

Correlational analyses were conducted to provide input for the statistical analysis (see Table 3). Structural equation modelling using LISREL 8.54 (Jöreskog and Sörbom 2003) was used to test and compare the various competing models. Four competing models were tested to examine the causal relationships between the needs, intrinsic motivation, persistence and performance. These models were:

1. The fully mediated model wave 1 (M1a): This model is visualised in Fig. 1 and represents the theory-driven SDT model at wave 1.

2. The fully mediated model wave 2 (M1b): This model is identical to M1a, but applies to wave 2.

3. The partially mediated model wave 1 (M2a), i.e., model M1a extended with direct paths from the three needs to performance and persistence.

4. The partially mediated model wave 2 (M2b).

In addition, several follow-up analyses were conducted, examining whether effects could be constrained across waves (unconstrained model M3 versus constrained models M4 and M5). Finally, insignificant effects were omitted (model M6). With regard to model fit, values of 0.90 or better indicate good fit for the Non-Normed Fit Index (NNFI) and values of 0.10 and lower are adequate for the Root Mean Square Error of Approximation (RMSEA) (Byrne 2009).

\section{Results}

The hypotheses concerned the associations among the study variables within each wave (hypothesis 1; see Fig. 1) and whether these associations were the same for both waves 
(hypothesis 2). To this aim, a series of single- and multiple-group structural equation analyses were conducted. Table 4 presents the fit indices for the models that were tested. First, it was examined for each wave whether a full (model M1a/M1b) or partial mediation model (M2a/M2b) applied. As Table 4 shows, at time 1, the full mediation model (M1a) fitted the data acceptably well, $X^{2}(d f=7, N=476)=15.3$, RMSEA $=0.05$, NNFI $=0.95$, but the partial mediation model (M2a) fitted the data significantly better, $\Delta X^{2}(d f=6, N=476)=$ $14.3, p<0.05$. Similar findings were obtained at time 2 . Whereas the full mediation model M1b could not be accepted, $X^{2}(d f=1, N=518)=38.7$, RMSEA $=0.10, \mathrm{NNFI}=0.80$, the partial mediation model M2b fitted the data acceptably well, $X^{2}(d f=1, N=518)=2.6$, RMSEA $=0.06, \mathrm{NNFI}=1.00$, and significantly better than the partial mediation model $\mathrm{M} 1 \mathrm{~b}$, $\Delta X^{2}(d f=6, N=518)=36.2, p<0.001$ (hypotheses $1 \mathrm{a}(\mathrm{i})$ and (ii) rejected, hypotheses $1 \mathrm{~b}(\mathrm{i})$ and (ii) supported).

To examine whether the effect estimates of the partial mediation model varied across waves (hypothesis 2), an additional multi-group analysis was conducted in which the associations among the cluster of needs, intrinsic motivation and the two performance measures were constrained to be equal across waves (model M4), relative to a model in which these associations could vary across waves (model M3). Although model M4 proved to be acceptable, $X^{2}(d f=13, N=994)=36.0$, RMSEA $=0.06$, NNFI=0.93, it fitted the data significantly worse than the unconstrained model M3, $\Delta X^{2}(d f=11, N=994)=32.5, p<$ 0.001. Thus, at least one effect estimate varied significantly across waves.

Further inspection revealed that the relation between perceived autonomy and intrinsic motivation varied significantly across waves. The same applied for perceived relatedness and intrinsic motivation. These effects were allowed to vary across groups (model M5), yielding acceptable fit, $X^{2}(d f=11, N=994)=9.60$, RMSEA=0.00, NNFI=1.01. Finally, several effects that did not differ significantly from zero were omitted, yielding a final model (M6) that fitted the data very well, $X^{2}(d f=17, N=994)=19.76$, RMSEA=0.02, $\mathrm{NNFI}=0.99$. Figure 3 presents the findings graphically.

As Fig. 3 shows, performance was unrelated to intrinsic motivation at both waves. However, persistence was positively affected by perceived competence and intrinsic motivation at both waves, which is in line with hypothesis $1 \mathrm{~b}$ on partial mediation. Furthermore, performance was directly affected by perceived competence. Interestingly,

Table 4 Comparison of the model fit for the within-wave associations among perceived competence/ autonomy/relatedness, intrinsic motivation and two performance indicators

\begin{tabular}{|c|c|c|c|c|c|}
\hline \multicolumn{2}{|c|}{ Model } & \multirow{2}{*}{$\frac{X^{2}}{15.3}$} & \multirow{2}{*}{$\frac{d f}{7}$} & \multirow{2}{*}{$\frac{\text { RMSEA }}{0.05}$} & \multirow{2}{*}{$\frac{\text { NNFI }}{0.95}$} \\
\hline M1a & Full mediation model (wave 1) & & & & \\
\hline M1b & Full mediation model (wave 2) & 38.7 & 7 & 0.10 & 0.80 \\
\hline $\mathrm{M} 2 \mathrm{a}$ & Partial mediation model (wave 1) & 0.96 & 1 & 0.04 & 1.00 \\
\hline \multirow[t]{3}{*}{$\mathrm{M} 2 \mathrm{~b}$} & Partial mediation model (wave 2) & 2.55 & 1 & 0.06 & 0.93 \\
\hline & $\Delta X^{2, \text { M1a-M2a }}$ (wave 1) & $14.34 *$ & 6 & & \\
\hline & $\Delta X^{2, \mathrm{M} 1 \mathrm{~b}-\mathrm{M} 2 \mathrm{~b}}$ (wave 2) & $36.15^{* *}$ & 6 & & \\
\hline M3 & M2a/M2b: effects unconstrained across waves & 3.51 & 2 & 0.04 & 0.97 \\
\hline \multirow[t]{2}{*}{ M4 } & M3: effects M2a/M2b constrained across waves & 36.05 & 13 & 0.06 & 0.93 \\
\hline & $\Delta X^{2, \mathrm{M} 4-\mathrm{M} 3}$ & $32.54 * *$ & 11 & & \\
\hline M5 & M4 plus effects of PercAU and PercRE on IM vary across waves & 9.60 & 11 & 0.00 & 1.01 \\
\hline M6 & M5, insignificant effects omitted & 19.76 & 17 & 0.02 & 0.99 \\
\hline
\end{tabular}

$* p<0.05, * * p<0.001$ 


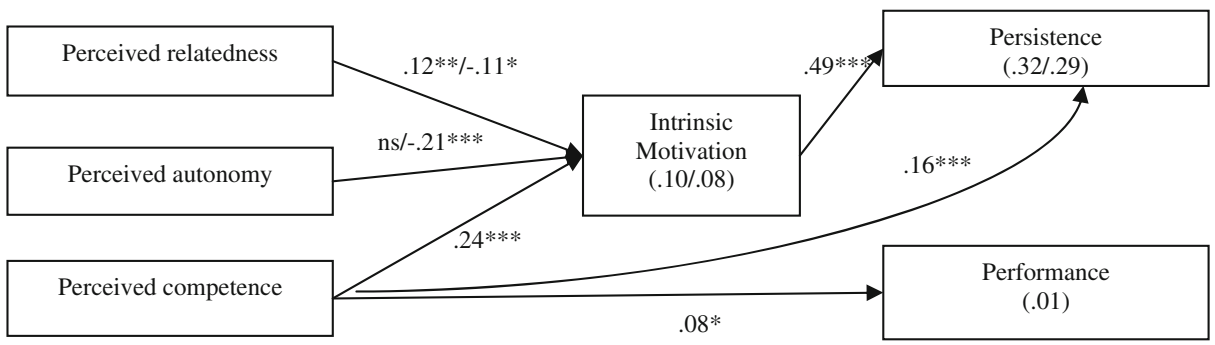

Fig. 3 Results of a two-group structural equation analysis. If one estimate is given, this effect applies to both waves; if two estimates are given, the first refers to wave 1 and the second refers to wave 2. $R^{2} \mathrm{~s}$ are given in brackets

Fig. 3 shows that the effects of need for relatedness and need for autonomy on intrinsic motivation varied across waves. Whereas the effects of these two needs on motivation were positive for relatedness and absent for autonomy at the first wave, both effects were negative at the second wave. Thus, when participants were familiar with the task to be performed, those with a high perceived relatedness (i.e. who felt at ease in class) and those with a high perceived autonomy (i.e. who felt they could decide themselves how to do the task) expressed less intrinsic motivation for the task and vice versa (see our discussion of the results).

\section{Discussion}

Discussion of our findings

SDT is often quoted and used as a theoretical base, also in educational research. However, the exact relations specified in this theory are not well documented for the dynamic motivation process in the actual classroom in real time. Questions remain about its applicability across time and learning episodes. SDT has often been tested with unfamiliar and novel tasks, with relatively intrinsically motivated participants who perform a task at only one occasion. However, the classroom reality is often quite different: tasks are repeated over and over and many students experience these repeated tasks as boring (Niemiec and Ryan 2009). It is common knowledge that adolescents have a lower intrinsic motivation than younger students (Eccles et al. 1993) and that they experience peer pressure to have a negative attitude towards repetitive tasks and school in general (Ryan 2000). Therefore, this study investigated the extent to which the theoretical hierarchical model from the perspective of SDT also holds up in secondary education students while they are working on unfamiliar tasks that have become familiar. We attempted to contribute to address applicability of the hierarchical SDT model across various learning episodes in prevocational secondary education.

To this aim, structural equation modelling was used to test and compare two basic models for the associations among performance/persistence, intrinsic motivation and the need for relatedness, autonomy and competence. The first model was in line with the assumption in SDT that the associations between the need for relatedness, autonomy and competence on one hand and persistence/performance on the other would be fully mediated through intrinsic motivation. The second basic model proposed that the needs for relatedness, autonomy and competence would also directly be related to persistence and 
performance (partial mediation). Our findings showed that, when students work on a task, the partial mediation model fitted the data significantly better than the full mediation model (as predicted by SDT), irrespective of the participants' familiarity with the task at hand. Persistence was positively affected by perceived competence and intrinsic motivation at both waves.

A close look at Fig. 3 reveals several findings that were not predicted by SDT. First, performance (i.e. test score) was not influenced by intrinsic motivation as would be predicted by SDT. It is directly affected by perceived competence. This association is very small (0.08), and performance is not affected by one of the other predictors in the model. Chen and Jang (2010) also failed to find support for motivation to predict learning outcomes in an online learning environment. A plausible explanation why the expected relations were not found in the present study is that the effect of intrinsic motivation on performance might be a long-term effect (i.e. takes multiple years to develop). Students who experience intrinsic motivation to explore and understand certain subject matters will gradually be rewarded for this: they will understand the subject matter better which in turn may further their performance in the long term.

Second, the association between perceived competence and persistence is not fully mediated by intrinsic motivation, as expected from the hierarchical SDT model. A direct path between perceived competence and persistence emerged; intrinsic motivation thus only partly explains the relation between perceived competence and persistence. These findings suggest that students who feel confident in their ability to do well on the assignment experience the task as more enjoyable and in turn are more willing to persist on the task (i.e. are more curious to know how they can apply the learned skills again). In addition to this indirect effect on persistence, the direct effect suggests that confident students are more persistent. Positive direct associations between competence, autonomy and relatedness with an outcome variable (i.e. wellbeing) were also reported by Véronneau et al. (2005).

Strikingly, not all effect estimates were identical across waves. The effects of perceived autonomy and relatedness on intrinsic motivation varied significantly across waves. Whereas the effects of these two needs on intrinsic motivation were positive or absent at the first wave, these effects were negative at the second wave. This implies that, when students were familiar with the task to be performed, those who perceived their relatedness and/or autonomy as high became less intrinsically motivated for the task. In other words, they were possibly bored with the task. This plausible but speculative finding is in conflict with SDT. But even more remarkable, those who perceived their relatedness and/or autonomy as low became more intrinsically motivated for the task. How can these conflicting findings be interpreted?

In line with SDT, students working on an unfamiliar task may or may not be challenged by its novelty, if they are, they will enthusiastically explore the task. If they are not challenged, they will report low intrinsic motivation. When the task becomes familiar, the missing aspect of novelty might create a lower need for autonomously exploring the task. Consequently, students who report high autonomy might become bored during a familiar task. On the other hand, students who report low perceived autonomy in relation to a familiar task might signal that the task does not pose a challenge for them (i.e. they know which strategies to use) and that their need for autonomy is at a satisfactory level, hence they might express more intrinsic motivation under these circumstances than when they are left to their own devices.

With regard to the need for relatedness, it is suggested that students who feel highly related to their classmates are more intrinsically motivated to do an unfamiliar task because they feel confident and safe to explore the novel task. These students 
feel confident with regard to a positive response if needed of other students and the teacher while fulfilling the task. However, when the novelty of the task is gone, this effect might be reversed. Students who feel highly related to their classmates might become less intrinsically motivated during the familiar task because the peer group pressures them to have a negative attitude towards the repetitive task (Ryan 2000), which are commonly seen in classrooms with a strong extrinsic orientation. Conversely, students who do not feel highly related to their classmates probably do not feel pressured by their peers and might have enjoyed doing a task that was familiar to them. Note that our results with regard to social relatedness are based on a subscale that showed Cronbach's $\alpha$ below the Cronbach and Shavelson (2004) standard. Our conclusions with regard to relatedness are, therefore, tentative.

Finally, the need for competence and its effect on intrinsic motivation did not vary across learning episodes. In line with SDT, students' perceived competence was positively associated with their reported intrinsic motivation. Despite the fact that our findings do not fully support the predictions made by SDT and that our conclusions are speculative, they demonstrate the importance of students' psychological needs in their functioning in the classroom. Our findings urge SDT researchers to take more account of the dynamic aspects of the learning and motivation process.

\section{Limitations}

A limitation of this study is that only measures to capture participants' perceived competence, relatedness and autonomy were included. Unfortunately, no information on their actual need for competence, relatedness and autonomy was gathered. Information on need fulfilment (i.e. the difference between the perceived level and actual need of the three basic needs) might provide additional information on the applicability of SDT in an extrinsically oriented environment such as classrooms. Information on need fulfilment would allow researchers to analyse data simultaneously for students with, for example, a high need for autonomy and students who have a low need for autonomy.

Second, although reliability coefficients of our key constructs were mainly above the cutoff point (with $\alpha$ being equal or exceeding 0.70 ), conclusions on relatedness (with reliability coefficients of 0.55 and 0.60 at waves 1 and 2, respectively) need to be drawn with some caution. Note that these relatively low reliabilities imply that the estimates for the associations between relatedness and the other study concepts will have been estimated conservatively.

\section{Theoretical implication}

Our research provides some evidence that the SDT model does not work similarly in all situations. The hierarchical model as represented in Fig. 1 was only partly confirmed in the present study. In this study, the SDT model was put to the test in situations that are commonly found in educational settings (students with low intrinsic motivation, tasks that are repeated over and over again and a negative peer group pressure towards learning). The relations assumed by SDT were not exactly the same at different waves within the same group of students and the relatively low explained variance of intrinsic motivation $(0.10$ / 0.08 ) indicates that also other variables were implicated in our study. In this sense, our findings show that the hierarchical SDT model is theoretically useful but practically challenging in the sense that the associations proposed in the model are subject to temporal and situational variations. Future research should attempt to shed more light on these issues. 
Practical implication

In the classroom, students are often confronted with similar tasks. On one hand, this is due to the educational benefit of repetition of tasks in order to learn a specific skill. On the other hand, this is also caused by the difficulty to align education in such a way that it meets each individual student's specific interests and needs at a specific point in time. Investigating the applicability of the SDT model within familiar as well as unfamiliar task contexts is, therefore, interesting and crucial, especially because the current research revealed that the process of motivation may vary across waves. Practically, this raises the question what teachers can do to appeal to their students' intrinsic motivation in different types of tasks in different situations. The relevance of teacher support for students' perceived competence, relatedness and autonomy is not acknowledged in this paper. But former research suggests that this should be taken into account (e.g. Reeve and Jang 2006). Further, it is beyond the scope of this text to go into great detail, but some authors have pointed to the possibilities offered by new learning technologies. Information and communication technology (ICT) may facilitate teachers to individualise education and to increase the variability of learning tasks. In an attempt to transform students' passive study behaviour into more active engagement, 'new' learning concepts have emerged, such as independent learning, self-regulated learning, informal learning, active learning, problem-based learning and work-based learning. Several researchers have combined social constructivism and ICT which is sometimes referred to as 'new learning' (for an overview, see Simons et al. 2000). There is a growing body of literature (e.g. Martens et al. 2004, 2007) that tries to explore these ICT possibilities (such as web-based learning, authentic tasks and the use of large electronic databases with educational content) in relation to the impact on motivation. The current study provides further evidence that prolonged research and development in this line is highly needed to solve important motivational problems in education.

Open Access This article is distributed under the terms of the Creative Commons Attribution Noncommercial License which permits any noncommercial use, distribution, and reproduction in any medium, provided the original author(s) and source are credited.

\section{References}

Benware, C. A., \& Deci, E. L. (1984). Quality of learning with an active versus passive motivational set. American Educational Research Journal, 21, 755-765.

Black, A. E., \& Deci, E. L. (2000). The effects of instructors' autonomy support and students' autonomous motivation on learning organic chemistry: A self-determination theory perspective. Science Education, $84,740-756$.

Boekaerts, M. (1987). Situation-specific judgments of a learning task versus overall measures of motivational orientation. In E. De Corte, H. Lodewijks, R. Parmentier, \& P. Span (Eds.), Learning and instruction: European research in an international context (Vol. 1, pp. 169-179). Oxford: Pergamon.

Boekaerts, M., Cascallar, E., Costigan, T., \& Rozendaal, J. S. (2008). Capturing the Multiple Components of Self-regulated Writing: A Systemic Approach. Paper presented at the 29th International Congress of Psychology, Berlin, Germany.

Burton, K. D., Lydon, J. E., D’Alessandro, D. U., \& Koestner, R. (2006). The differential effects of intrinsic and identified motivation on well-being and performance: Prospective, experimental, and implicit approaches to self-determination theory. Journal of Personality and Social Psychology, 91, 750-762. 
Byrne, B. M. (2009). Structural equation modeling with AMOS: Basic concepts, applications, and programming. Mahwah: Erlbaum.

Chen, A., \& Darst, P. W. (2001). Situational interest in physical education: A function of learning task design. Research Quarterly for Exercise and Sport, 72, 150-164.

Chen, K. C., \& Jang, S. J. (2010). Motivation in online learning: Testing a model of self-determination theory. Computers in Human Behavior, 26, 741-752.

Cronbach, L. J., \& Shavelson, R. J. (2004). My current thoughts on coefficient alpha and successor procedures. Educational and Psychological Measurement, 64, 391-418.

Deci, E. L., \& Ryan, R. M. (1985). Intrinsic motivation and self-determination in human behavior. New York: Plenum Press.

Deci, E. L., \& Ryan, R. M. (2000). The "what" and "why" of goal pursuits: Human needs and the selfdetermination of behavior. Psychological Inquiry, 11, 227-268.

Eccles, J. S., Midgley, C., Wigfield, A., Miller Buchanan, C., Reuman, D., Flanagan, C., \& Mac Iver, D. (1993). Development during adolescence: The impact of stage-environment fit on young adolescents' experiences in schools and in families. American Psychologist, 48, 90-101.

Grolnick, W. S., \& Ryan, R. M. (1987). Autonomy in children's learning: An experimental and individual difference investigation. Journal of Personality and Social Psychology, 52, 890-898.

Grouzet, F. M. E., Vallerand, R. J., Thill, E. E., \& Provencher, P. J. (2004). From environmental factors to outcomes: A test of an integrated motivational sequence. Motivation and Emotion, 28, 331-346.

Jöreskog, K. G., \& Sörbom, D. (2003). LISREL 8.54 [computer manual]. Chicago: Scientific Software.

Koestner, R., Ryan, R. M., Bernieri, F., \& Holt, K. (1984). Setting limits on children's behavior: The differential effects of controlling versus informational styles on intrinsic motivation and creativity. Journal of Personality, 52, 233-248.

Könings, K. D., Brand-Gruwel, S., Van Merriënboer, J. J. G., \& Broers, N. J. (2008). Does a new learning environment come up to students' expectations? A longitudinal study. Journal of Educational Psychology, 100, 535-548.

Mansfield, C. F., \& Wosnitza, M. (2010). Motivation goals during adolescence: A cross-sectional perspective. Issues in Educational Research, 20, 149-165.

Martens, R., Gulikers, J., \& Bastiaens, Th. (2004). The impact of intrinsic motivation on e-learning in authentic computer tasks. Journal of Computer Assisted Learning, 20, 368-376.

Martens, R., Bastiaens, Th, \& Kirschner, P. A. (2007). New learning design in distance education: Its impact on student perception and motivation. Distance Education, 28, 81-95.

McAuley, E., Duncan, T., \& Tammen, V. V. (1989). Psychometric properties of the Intrinsic Motivation Inventory in a competitive sport setting: A confirmatory factor analysis. Research Quarterly for Exercise and Sport, 60, 48-58.

Minnaert, A., Boekaerts, M., \& De Brabander, C. (2007). Autonomy, competence, and social relatedness in task interest within project-based education. Psychological Reports, 101, 574-586.

Niemiec, C. P., \& Ryan, R. M. (2009). Autonomy, competence, and relatedness in the classroom: Applying self-determination theory to educational practice. Theory and Research in Education, 7, 133-144.

Reeve, J. (2002). Self-determination theory applied to educational settings. In E. L. Deci \& R. M. Ryan (Eds.), Handbook of self-determination research (pp. 183-203). Rochester: University of Rochester Press.

Reeve, J., \& Jang, H. S. (2006). What teachers say and do to support students' autonomy during a learning activity. Journal of Educational Psychology, 98, 209-218.

Ryan, A. M. (2000). Peer groups as a context for the socialization of adolescents' motivation, engagement, and achievement in school. Educational Psychologist, 35, 101-111.

Ryan, R. M., \& Deci, E. L. (2000a). Intrinsic and extrinsic motivations: Classic definitions and new directions. Contemporary Educational Psychology, 25, 54-67.

Ryan, R. M., \& Deci, E. L. (2000b). Self-determination theory and the facilitation of intrinsic motivation, social development, and well-being. American Psychologist, 55, 68-78.

Ryan, R. M., \& Grolnick, W. S. (1986). Origins and pawns in the classroom. Self-report and projective assessments of individual differences in children's perceptions. Journal of Personality and Social Psychology, 50, 550-558.

Ryan, R. M., \& Weinstein, N. (2009). Undermining quality teaching and learning: A self-determination theory perspective on high-stakes testing. Theory and Research in Education, 7, 224-233.

Simons, R., Van der Linden, J., \& Duffy, T. (2000). New learning. Dordrecht: Kluwer Academic.

Standage, M., Duda, J. L., \& Ntoumanis, N. (2006). Students' motivational processes and their relationship to teacher ratings in school physical education: A self-determination theory approach. Research Quarterly for Exercise and Sport, 77, 100-110.

Tsai, Y., Kunter, M., Lüdtke, O., Trautwein, U., \& Ryan, R. M. (2008). What makes lessons interesting? The role of situational and individual factors in three school subjects. Journal of Educational Psychology, 100, 460-472. 
Vallerand, R. J. (1997). A hierarchical model of motivation. Advances in Experimental Social Psychology, $29,271-360$.

Van Nuland, H. J. C., Dusseldorp, E., Martens, R. L., \& Boekaerts, M. (2010). Exploring the motivation jungle: Predicting performance on a novel task by investigating constructs from different motivation perspectives in tandem. International Journal of Psychology, 45, 250-259.

Véronneau, M. H., Koestner, R. F., \& Abela, J. R. Z. (2005). Intrinsic need satisfaction and well-being in children and adolescents: An application of the self-determination theory. Journal of Social and Clinical Psychology, 24, 280-292.

Zimmerman, B. J., \& Kitsantas, A. (1999). Acquiring writing revision skill: Shifting from process to outcome self-regulatory goals. Journal of Educational Psychology, 91, 241-250.

Hanneke J. C. Van Nuland. Centre for the Study of Education and Instruction, Faculty of Social and Behavioral Sciences, Leiden University, Wassenaarseweg 52, P.O. Box 9555, NL-2300 RB, Leiden, The Netherlands. Phone: +31-71-5273393. E-mail: hannekeknoop@hotmail.com; Website: http://www.fsw. leidenuniv.nl/pedagogiek/onderwijsstudies/medewerkers/vannuland.html

Current themes of research:

Motivation. adolescents. self-determination theory. self-regulation theory.

Most relevant publications in the field of Psychology of Education:

van Nuland, H.J.C., Dusseldorp, E., Martens, R.L., \& Boekaerts, M. (2010). Exploring the motivation jungle: Predicting performance on a novel task by investigating constructs from different motivation perspectives in tandem. International Journal of Psychology, 45(4), 250-259.

Toon W. Taris. Department of Social and Organizational Psychology, Utrecht University, Heidelberglaan 1, P.O. Box 80.140, NL-3508 TC, Utrecht, The Netherlands. Phone: +31-30-2534812. E-mail: t.taris@uu. nl; Website: http://medewerkers.fss.uu.nl/ttaris

Current themes of research:

Motivation. structural equation modelling. health.

Most relevant publications in the field of Psychology of Education:

Taris, T. W., Kompier, M. A. J., Geurts, S. A. E., Houtman, I. L. D., \& Van den Heuvel, F. F. M. (2010). Professional efficacy, exhaustion, and work characteristics among police officers: A longitudinal test of the learning-related predictions of the demand-control model. Journal of Occupational and Organizational Psychology, 83, 455-474.

Monique Boekaerts. Centre for the Study of Education and Instruction, Faculty of Social and Behavioral Sciences, Leiden University, Wassenaarseweg 52, P.O. Box 9555, NL-2300 RB, Leiden, The Netherlands. Phone: +31-71-5273403. E-mail: boekaerts@fsw.leidenuniv.nl; Website: http://www.fsw. leidenuniv.nl/pedagogiek/onderwijsstudies/medewerkers/boekaerts.html

Current themes of research:

Motivation. self-regulation theory. multiple goals.

Most relevant publications in the field of Psychology of Education:

Boekaerts, M., van Nuland, H.J.C., \& Martens, R.L. (2010). Perspectives on motivation: What mechanisms energise students' behaviour in the classroom. International Handbook of Psychology in Education, 535-568. Bingley: Emerald Group Publishing Limited. 
Boekaerts, M., \& Rozendaal, J.S. (2010). Using multiple calibration indices in order to capture the complex picture of what affects students' accuracy of feeling of confidence. Learning and Instruction, 20, 372-382.

Boekaerts, M. (2009). Goal-directed behavior in the classroom. In: Wentzel, K., \& Wigfield, A. (Eds.), Handbook on motivation at school (pp. 105-122). New York: Routledge.

Rob. L. Martens. Centre for the Study of Education and Instruction, Faculty of Social and Behavioral Sciences, Leiden University, Wassenaarseweg 52, P.O. Box 9555, NL-2300 RB, Leiden, The Netherlands. Phone: +31-71-5273403. E-mail: rob.martens@ou.nl; Website: http://www.fsw.leidenuniv.nl/pedagogiek/ onderwijsstudies/medewerkers/martens.html

Current themes of research:

Motivation. self-determination theory. computer-based learning. professional development.

Most relevant publications in the field of Psychology of Education:

Martens, R., Bastiaens, Th., \& Kirschner, P. A. (2007). New learning design in distance education: its impact on student perception and motivation. Distance Education, 28, 81-95.

Martens, R., Gulikers. J., \& Bastiaens, Th. (2004). The impact of intrinsic motivation on e-learning in authentic computer tasks. Journal of Computer Assisted Learning, 20, 368-376. 